\title{
Extended Phylogeny and Extraintestinal Virulence Potential of Commensal Escherichia coli from Piglets and Sows
}

\author{
Ewa Bok ${ }^{1, *}$, Aleksandra Kożańska ${ }^{2}$, Justyna Mazurek-Popczyk ${ }^{1}$, Magdalena Wojciech ${ }^{3}$ and \\ Katarzyna Baldy-Chudzik ${ }^{1}$
}

1 Department of Microbiology and Molecular Biology, Collegium Medicum, University of Zielona Góra, 65-561 Zielona Góra, Poland; j.mazurek-popczyk@cm.uz.zgora.pl (J.M.-P.);

k.baldy-chudzik@cm.uz.zgora.pl (K.B.-C.)

2 Department of Biotechnology, Faculty of Biological Sciences, University of Zielona Góra, 65-561 Zielona Góra, Poland; ola19937@onet.eu

3 Department of Mathematical Statistics and Econometrics, Faculty of Mathematics, Computer Science and Econometrics, University of Zielona Góra, 65-516 Zielona Góra, Poland; m.wojciech@wmie.uz.zgora.pl

* Correspondence: e.bok@cm.uz.zgora.pl; Tel.: +48-68-328-73-33

Received: 31 October 2019; Accepted: 4 December 2019; Published: 6 January 2020

\begin{abstract}
Commensal Escherichia coli, naturally occurring in the intestinal tract, can be the origin of extraintestinal pathogenic E. coli (ExPEC) strains. ExPEC causes high mortality and significant economic losses in the swine industry in several countries and poses a serious threat to public health worldwide. The aim of this study was to analyze the extended phylogenetic structure and extraintestinal virulence potential in two groups of commensal $E$. coli isolates from post-weaning piglets and sows. The phylogenetic assignment to eight groups was determined using the revised Clermont phylogenetic typing method in quadruplex PCR. Identification of extraintestinal virulence genes (VGs) and adhesin operon genes was performed using multiplex or simplex PCR. The revised phylogenetic assignment allowed us to distinguish E. coli with significantly higher (groups $C$ and F) or lower (group E) virulence potential in isolates from piglets. The majority of the tested VGs occurred more frequently in isolates from piglets than from sows, with statistically significant differences for seven genes: fim $H$, pap $A H$, iut $A$, iroN, ompT, traT, and iss. Complete operons for type I and P fimbriae significantly prevailed among E. coli from piglets. This study provides insight into the extended phylogenetic structure of porcine commensal E. coli and showed that these strains, particularly from piglets, constitute a considerable reservoir of extraintestinal VGs and may increase the potential risk of extraintestinal infections.
\end{abstract}

Keywords: commensal Escherichia coli; piglets; sows; virulence genes (VGs); phylogenetic typing; nonlinear mixed models

\section{Introduction}

Commensal Escherichia coli strains are members of the facultative anaerobic natural microbiota of humans and animals [1]. These bacteria are usually harmless, but part of their population can become extraintestinal pathogenic E. coli (ExPEC). ExPEC have a fecal origin, occur asymptomatically in the intestinal tract, and sometimes can colonize extraintestinal niches and cause serious diseases [2,3]. Typical extraintestinal infections include urinary tract infections (UTI), pyelonephritis, sepsis, pneumonia, and meningitis [4-6]. The virulence potential of ExPEC depends on the various extraintestinal virulence-associated factors in bacteria-host interactions, rather than a simple mechanism [7]. Characteristic ExPEC virulence factors include various adhesins (type I and P fimbriae), 
iron acquisition and utilization systems (aerobactin and salmochelin siderophores), protectins (structural components of the bacterial outer membrane), toxins (hemolysin, cytotoxic necrosis factor), and biofilm formation factor (antigen 43). These virulence factors facilitate colonization and invasion of the host, as well as avoidance or disruption of host defense mechanisms [8,9]. ExPEC strains were defined by Johnson et al. [10] as E. coli isolates containing two or more of the following virulence markers: papA/papC, sfa/foc, afa/dra, kpsMTII, and iutA. Virulence genes (VGs) responsible for pathogenicity are usually encoded on pathogenicity islands (PAIs), plasmids, and other mobile genetic elements, and can thus be transmitted via horizontal gene transfer (HGT) between various E. coli strains [2]. Commensal or pathogenic bacteria may, in a single HGT event, acquire a mobile genetic element carrying multiple VGs, antimicrobial-resistance genes, or other genes encoding features that offer a niche advantage $[11,12]$. Many studies have suggested a strong association between virulence gene carriage and the phylogenetic type of E. coli strains $[7,13,14]$.

The population structure of $E$. coli is predominantly clonal and strains can be classified into one of eight phylogenetic groups: A, B1, B2, C, D, E, F, and cryptic clade I [15]. In humans, commensal E. coli, with no pathogenic features, most often represent group A or B1, whereas the majority of E. coli responsible for extraintestinal infections are classified into B2 and D phylogroups. Group E is related to group D, while group $\mathrm{F}$ is related to the main group, B2 [1,7]. Factors that shape the phylogenetic structure of E. coli are: environment, gut anatomy, physiology, and diet. In animals, the main environmental force influencing the phylogenetic structure of the E. coli is the domestication status of the host [16]. Domesticated animals have a lower proportion of B2 strains than their wild counterparts and a higher proportion of A strains [17]. In the phylogenetic structure of the commensal E. coli strains derived from pigs, phylogroup A dominates, followed by group B1. Strains classified into phylogroups D and B2 occur less frequently [12,18-20]. Porcine ExPEC are mainly distributed among phylogroups A, B1, and D and rarely among the B2 group [6]. We previously described the phylogeny of commensal E. coli from post-weaning piglets and sows, and our study showed significant differences in distribution of phylogroups A and B1. Among strains from piglets, phylogenetic group B1 prevailed significantly, while in sows, E. coli in group A were the most frequent. The strains belonging to phylogroup B2 are the least frequent in both groups [21]. In the literature, there is information concerning the phylogeny of porcine commensal E. coli based on the previous Clermont phylogenetic typing method [22], but there is a lack of analyses using the new, revised Clermont scheme [15]. Changes in the designation of phylogenetic type are important in identifying new groups of analyzed strains. Phylogenetic typing by the new scheme results in re-distribution of some of the identified isolates into new groups from their original designation and reveals a more complex phylogenetic structure of the analyzed strains [15,23]. The revised Clermont phylotyping method is a useful tool for subtyping various ExPEC lineages, allowing differentiation of E. coli strains with higher or lower virulence potential [23]. Reclassification of porcine E. coli from our collection may show the differences between the phylogenetic pattern characteristic for post-weaning piglets and sows and distinguish the phylogroups with different pathogenic potential.

Infections caused by ExPEC strains occur worldwide and are associated with great economic cost [24]. ExPEC is an important pathogen in the swine industry, in several countries, responsible for substantial economic losses [25-27]. Porcine ExPEC is an important pathogen causing UTI-a significant cause of death in adult animals [6]. Other diseases induced by these strains are coliform mastitis, meningitis, pneumonia, arthritis, and septicemia [6,28]. Similar virulence profiles and serogroups have been detected both in porcine and human ExPEC, suggesting that there is a cross-infection possibility between human and pigs, and that these pathogens may have strong zoonotic potential $[6,28,29]$. Therefore, porcine ExPEC poses a high risk for food safety and public health security [30-32]. As mentioned above, the line between commensals and ExPEC is very thin. An example is E. coli clonal complex 10 (CC10), which is a commensal gastrointestinal inhabitant in pigs, other food-production animals, wild animals, and humans. On the other hand, certain strains of E. coli CC10 are known to cause extra-intestinal disease in pigs, dogs, and humans $[6,33,34]$. Therefore, it is important to 
investigate the presence of VGs, including in the commensal flora of food animals. It may give us information on the extent of the reservoir of VGs carried by commensal E. coli from pigs.

The scope of this study was to investigate the extended phylogeny and extraintestinal virulence potential of commensal E. coli isolated from two groups of healthy pigs (post-weaning piglets and sows). We aimed to compare the phylogenetic assignment using the revised (this study) and previous (the earlier data [21]) Clermont phylogenetic typing methods. The purpose was also the identification of the VGs typical for extraintestinal pathogens, their distribution in the phylogenetic structure, and genotypic analysis of two fimbrial operons for type I and P fimbriae among E. coli from piglets and sows.

\section{Materials and Methods}

\subsection{Sample Collection, Isolation, and Identification of Escherichia Coli (E. coli)}

The samples were derived from a pig breeding farm in Lubuskie Province (Western Poland) and were collected in 2011. Two groups of healthy pigs were included in the study. The first one consisted of 49 post-weaning piglets (6 weeks and 8 weeks old), and the second comprised 50 sows (5 months and 7 months old). Fresh fecal samples were collected only once, and E. coli was selected as described previously [21]. Briefly, fecal samples were plated on membrane Fecal Coliform (mFC) chromogenic agar (Merck, Darmstadt, Germany) and incubated at $44^{\circ} \mathrm{C}$ for $24 \mathrm{~h}$. The blue colonies typical for fecal coliforms were subcultured on the MacConkey's agar (Merck) and incubated at $37^{\circ} \mathrm{C}$ for $24 \mathrm{~h}$. The typical lactose fermenting colonies were randomly selected and identified by biochemical tests: Indole production, Methyl red reaction, Voges-Proskauer test, and Citrate utilization (IMVC). This study involved the same set of isolates as in the earlier study [21], namely 274 unique E. coli, from one to four per animal, 110 isolated from post-weaning piglets, and 164 from sows. The DNA extraction was carried out using the thermal cell lysis method, $1.5-3 \mu \mathrm{L}$ of the boiled bacterial supernatant was used as a template in all the PCR reactions.

\subsection{Extended Phylogenetic Grouping}

Phylogenetic analysis was performed using the revised Clermont phylogenetic typing method described by Clermont et al. in 2013. E. coli isolates were assigned to phylogroups A, B1, B2, D, and F using new quadruplex PCR. Additional specific screening, in a separate PCR reaction, was carried out to classify E. coli into phylogroups C and E and clade I [15,35-37]. Escherichia coli Reference (ECOR) collection strains (Institut Pasteur Collection, Paris, France) were examined in all PCR reactions as positive and negative controls, respectively.

\subsection{Virulence Genes (VGs) and Fimbrial Operons Genotyping}

The E. coli isolates were examined for the presence of the following extraintestinal VGs, representing five functional categories: (1) adhesins: fim $H$ (type 1 fimbriae), $p a p A H$, (P fimbriae), and sfaS (S fimbriae); (2) iron acquisition: $f y u A$ (yersiniabactin siderophore receptor), iut $A$ (aerobactin siderophore receptor), iroN (salmochelin siderophore receptor), ireA (iron-regulated element, siderophore receptor); (3) protectins: kpsMTII, kpsMT K1, kpsMT K2, kpsMT K5 (group II capsule with K1, K2 and K5 variants), kpsMTIII (group III capsule), ompT (outer membrane protein, protease), traT (serum resistance-associated outer membrane protein), and iss (increased serum survival); (4) toxins: cnf1 (cytotoxic necrotizing factor 1) and hlyA (alpha hemolysin); (5) biofilm formation: agn43, agn43 a, and agn43 b (antigen 43 , common, and alleles a and b). The VGs in functional categories were chosen according to the previous published data as typical for ExPEC strains [38-46]. The isolates positive for the adhesin genes fimH and pap $A H$ additionally were screened for the presence of the other operon genes: (1) fimB, fimE, fim $A$, fimI, and fim C and (2) papC, papEF, papG, and its variants (GI, GII and GIII), essential for expression of type 1 and $P$ fimbriae, respectively. Multiplex or simplex PCR-based genotyping was performed with primers and conditions previously described [38-46]. The PCR amplification mixture in a volume of $25 \mu \mathrm{L}$ contained: buffer solution (Thermo Scientific, Waltham, MA, USA), $2.5 \mathrm{mM} \mathrm{MgCl}_{2}$ (Promega, 
Madison, WI, USA), $0.5 \mathrm{mM}$ of each dNTP (Promega), $0.2 \mu \mathrm{M}$ of each primer (IDT, Coralville, IA, USA), $1 \mathrm{U}$ of Dream Taq Green DNA Polymerase (Thermo Scientific), and $3 \mu \mathrm{L}$ of DNA template. E. coli strains from the ECOR collection (Institut Pasteur Collection, Paris, France), Polish Collection of Microorganisms (Institute of Immunology and Experimental Therapy, Polish Academy of Sciences, Wroclaw, Poland), and from our collection of human fecal strains, known to possess (validated by sequencing) or lack the genes of interest, were examined in all PCR reactions as positive and negative controls, respectively. The PCR products were separated in $1.5 \%$ or $2 \%$ agarose gel electrophoresis and stained with ethidium bromide.

\subsection{Statistical Analysis}

The presence of VGs was categorized as $1=$ yes and $0=$ no. The relations between the presence of VGs and two groups of pigs were described using the logistic regression mixed model. In this approach, each individual with at least one strain positive for a virulence gene was considered as an individual with E. coli positive for these factors. The mixed logit model approach takes into account the correlated nature of the isolates derived from one pig.

In each case, we assume the mixed logistic regression with one random effect per animal (pig). Let $y_{i j}=1$ if the $j$ th isolate derived from the $i$ th pig has the virulence gene and $y_{i j}=0$ otherwise. In this case $i=1, \ldots, 99$ and $j=1, \ldots, n_{i}$ where $n_{i}$ is the number of isolates derived from the $i$ th pig. We consider the following model:

$$
\operatorname{logit}\left(\pi_{i j}\right)=\beta_{0}+\beta_{1} x_{i j}+b_{i}
$$

where $\pi_{i j}=P\left(y_{i j}=1 \mid b_{i}\right)$ is the conditional probability of gene presence for an individual random effect $b_{i}$ associated with the $i$ th pig, assumed to have a normal distribution with mean zero and variance $\sigma^{2}{ }_{b}$. The fixed effect, $x_{i j}$, is the categorical variable that can take two levels: piglets or sows, which is the reference category, and $\beta_{0}, \beta_{1}$ are regression coefficients.

The evaluations of the frequency of the gene combinations within type 1 and $\mathrm{P}$ fimbriae operons among the $E$. coli isolates from piglets and sows were tested using the chi-squared test for proportions or Fisher's exact test for proportions. Fisher's exact test was used when the assumptions of the chi-square test did not hold. The null hypothesis assumes that the proportions in isolates from piglets and sows are equal. The alternative hypothesis is one-sided and assumes that the proportion in one group of animals (piglets or sows) was lower or higher than in the other, as appropriate. In order to control the number of false positive results in a series of tests for comparing two proportions the method of false discovery rate (FDR) was used. The FDR Benjamini-Hochberg procedure (1995) allowed us to adjust the p-value in multiple testing. An analogous approach was used to compare the frequency of the E. coli isolates with VGs within phylogenetic groups.

In order to measure the strength of the associations for the cross tabulation of VGs of the E. coli isolates from both piglets and sows, the Goodman and Kruskal tau coefficient was calculated.

For all the statistical tests, the level of statistical significance was defined as 0.05 . The statistical analyses were performed using the program $\mathrm{R}$ ( $\mathrm{R}$ Core Team) [47-49].

\section{Results}

\subsection{Extended Phylogenetic Structure of E. coli}

Extended phylogenetic group classification revealed that $E$. coli isolates derived from piglets and sows differed significantly in their phylogenetic structure $(p=0.0005)$ (Figure 1$)$. The majority of $E$. coli from piglets (48.2\%) belonged to phylogroup B1, followed by A $(21.8 \%)$, the phylogroups B2, C, D, E, and $\mathrm{F}$ were identified at a lower frequency. None of these isolates were assigned to clade $\mathrm{I}$, and $3.6 \%$ of isolates did not belong to any known phylogroup and therefore were assigned as NT (not typeable). Among the E. coli isolates from sows, phylogroup A was the most frequent (48.2\%), followed by B1 $(23.2 \%)$, while phylogroups B2, D, E, F, and clade I occurred with a lower frequency. None of the 
isolates belong to group C and $4.9 \%$ were classified as NT. Phylogenetic groups B1, C, and E were significantly more frequent in the isolates from piglets as compared to sows, $p<0.0001, p=0.009$, and $p=0.005$, respectively. Conversely, phylogroups A and F significantly prevailed among the isolates from sows compared to piglets, $p<0.0001$ and $p=0.01$, respectively.

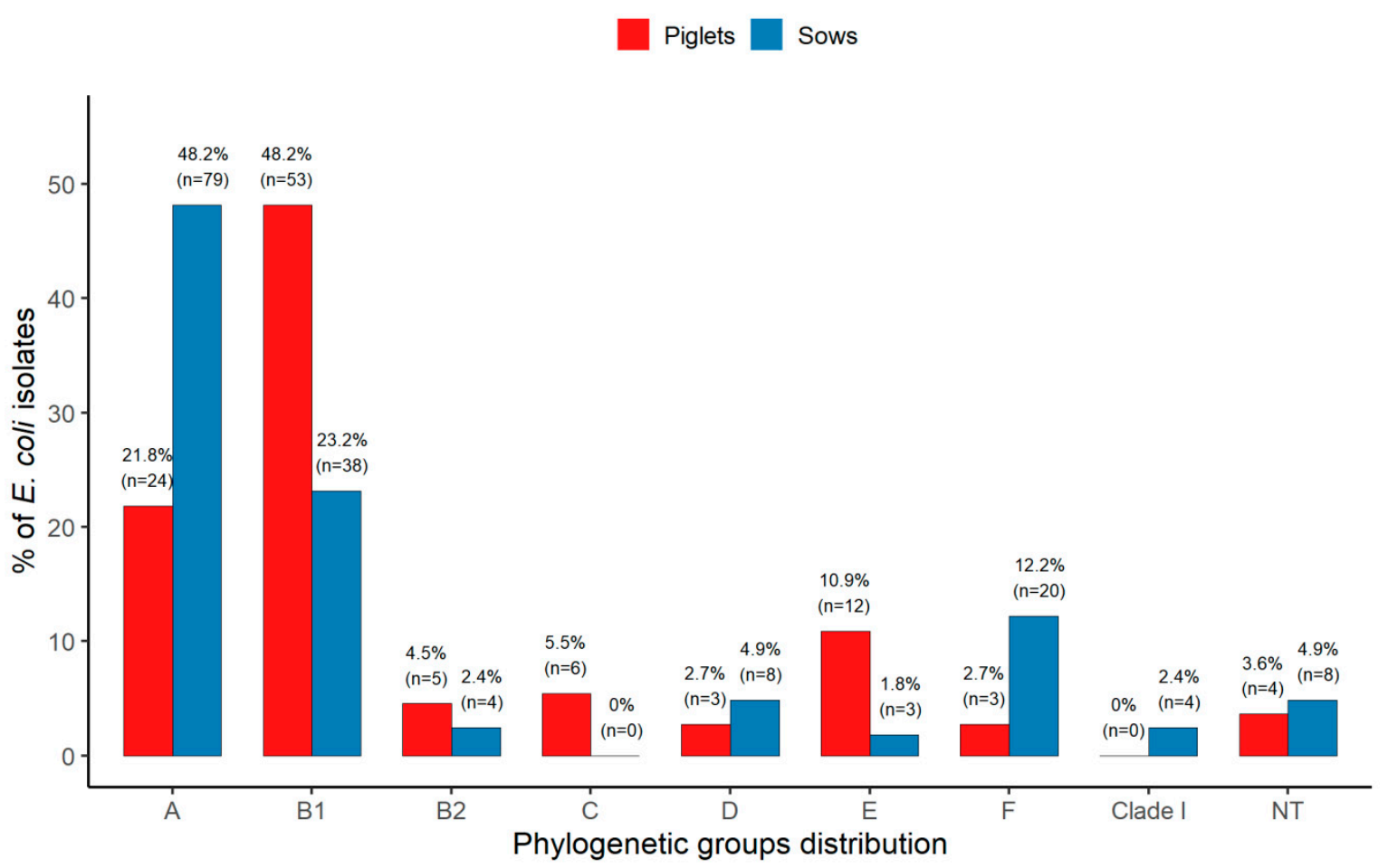

Figure 1. Extended phylogenetic structure of the Escherichia coli (E. coli) isolates derived from piglets and sows. Note: NT- not typeable.

All isolates were analyzed individually using the previous Clermont phylogenetic typing method (in earlier study [21]) and revised Clermont protocol (this study). The comparison of the previous and revised classification of the E. coli isolates is presented in Supplementary Table S1. The new phylogenetic classification for most isolates is consistent with the original one. Designation change rates were similar for both groups of isolates and were $27.2 \%$ and $31 \%$ among E. coli from piglets and sows, respectively. For the E. coli from piglets, the dominant phylogroup by the old typing scheme was $\mathrm{B} 1$ and after the revision, this category still dominated, while the greatest changes were noted for A to $\mathrm{C}$ re-classification (5.5\%) and $\mathrm{D}$ to $\mathrm{E}(10.9 \%)$. The majority of isolates from sows were typed as phylogroup A according to the old scheme and this category also dominated after revision, whereas a considerable number of isolates were re-classified from A to B1 (5.5\%) and from D to F (11.6\%).

\subsection{Prevalence of $V G s$}

To assess the virulence potential of commensal E. coli isolates from piglets and sows, we screened for a total of 15 genes that have been associated with extraintestinal disease caused by ExPEC. Each of these genes was present in at least one isolate. E. coli from piglets carried between 1 and $12 \mathrm{VGs}$, with a mean of 4.6 VGs per isolate. The isolates derived from sows possessed between 0 and $10 \mathrm{VGs}$, with a mean of 2.9 VGs per isolate. According to the definition (Johnson et al. [10]) 19 (17.3\%) of E. coli isolates from piglets and 13 (7.9\%) from sows were classified as ExPEC. One gene in the adhesins category $(s f a S)$ and two genes from the toxins category ( $c n f 1$ and $h l y A)$ were not detected in any of the isolates from sows. The most frequent gene from the adhesins category was fim $H$, with rates of $97.3 \%$ and $86.6 \%$ for isolates from piglets and sows, respectively. The iron acquisition category was most often represented by the iutA gene, which occurred with the frequency of $50.9 \%$ and $20.1 \%$ for E. coli from 
piglets and sows, respectively. Among the protectins category, the traT gene was the most prevalent with rates of $85.5 \%$ and $54.9 \%$ for isolates from piglets and sows, respectively. For the kpsMTII gene, the $\mathrm{K} 2$ variant was the most frequent $(7.3 \%)$ among the isolates from piglets but $\mathrm{K} 5(6.1 \%)$ was most frequent in E. coli from sows. The cnf1 gene occurred more often $(4.5 \%)$ than the $h l y A$ gene $(1.8 \%)$ in the toxins category, among $E$. coli from piglets. In the biofilm formation category, alleles a and $\mathrm{b}$ of the agn 43 gene were not frequent. The allele agn 43 a showed higher rates than allele agn $43 \mathrm{~b}$ with $4.5 \%$ and $1.8 \%$ for isolates from piglets and sows, respectively. The majority of the tested genes, $14 / 15$, occurred more frequently in isolates from piglets than from sows, with statistically significant differences for seven VGs: fimH, papAH, iutA, iroN, ompT, traT, and iss. The exceptions were the kpsMTIII gene and K1 variant of the kpsMTII gene, which were detected less frequently among isolates from piglets. Table 1 shows these results in detail.

Table 1. Frequency of virulence genes (VGs) by functional categories among E. coli isolates from piglets and sows. The test of statistical significance for fixed effect from the mixed logistic models with VG as the response and the animal as the independent variable.

\begin{tabular}{|c|c|c|c|}
\hline \multirow{2}{*}{$\begin{array}{c}\text { Functional Category } \\
\text { VG }\end{array}$} & \multicolumn{2}{|c|}{ Number (\%) of E. coli Isolates with VGs } & \multirow{2}{*}{$p$-Value } \\
\hline & $\begin{array}{c}\text { Piglets } \\
\mathrm{N}=\mathbf{1 1 0}\end{array}$ & $\begin{array}{c}\text { Sows } \\
N=164\end{array}$ & \\
\hline \multicolumn{4}{|l|}{ Adhesins } \\
\hline fimH & 107 (97.3) & $142(86.6)$ & $0.0065 *$ \\
\hline papAH & $13(11.8)$ & $8(4.9)$ & $0.0449 *$ \\
\hline$s f a S$ & $2(1.8)$ & 0 & - \\
\hline \multicolumn{4}{|l|}{ Iron acquisition } \\
\hline fyuA & $29(26.4)$ & $23(14.0)$ & 0.0931 \\
\hline iut $A$ & $56(50.9)$ & $33(20.1)$ & $<0.0001 *$ \\
\hline iroN & $43(39.1)$ & $29(17.7)$ & $0.0012 *$ \\
\hline ireA & $7(6.4)$ & $5(3.0)$ & 0.2313 \\
\hline \multicolumn{4}{|l|}{ Protectins } \\
\hline kpsMTII: & $12(10.9)$ & $10(6.1)$ & 0.2867 \\
\hline$-\mathrm{K} 1$ & $4(3.6)$ & $9(5.5)$ & 0.5026 \\
\hline$-\mathrm{K} 2$ & $8(7.3)$ & $9(5.5)$ & 0.7091 \\
\hline$-\mathrm{K} 5$ & $7(6.4)$ & $10(6.1)$ & 0.9264 \\
\hline kpsMTIII & $1(0.9)$ & $2(1.2)$ & 0.9971 \\
\hline ompT & $36(32.7)$ & $28(17.1)$ & 0.0175 * \\
\hline traT & $94(85.5)$ & $90(54.9)$ & $<0.0001$ * \\
\hline iss & $35(31.8)$ & $25(15.2)$ & 0.0143 * \\
\hline \multicolumn{4}{|l|}{ Toxins } \\
\hline cnf1 & $5(4.5)$ & 0 & - \\
\hline$h l y A$ & $2(1.8)$ & 0 & - \\
\hline \multicolumn{4}{|l|}{ Biofilm formation } \\
\hline agn $43:$ & $59(53.6)$ & $87(53.0)$ & 0.9275 \\
\hline$-a$ & $5(4.5)$ & $3(1.8)$ & 0.4890 \\
\hline$-b$ & $2(1.8)$ & $2(1.2)$ & 0.6874 \\
\hline
\end{tabular}

\subsection{Distribution of VGs according to Phylogenetic Groups}

Analysis of the distribution of VGs within phylogenetic groups revealed that there were more statistically significant differences among isolates from piglets than among isolates from sows (Table 2). The mean number of VGs for each phylogroup in isolates from piglets was: A - 4.6, B1—4, B2-10.6, C - 8, D-4.7, E-2.6, F-7.7, and NT-2.5. The mean number of VGs for each phylogroup among isolates from sows was: A-2.5, B1-3.6, B2-3.8, D-2.1, E-2.7, F-2.9, clade I-1.8, and NT-5. Generally, in the E. coli from piglets, the frequencies of the particular genes in the iron acquisition, 
protectins, and biofilm formation categories were significantly lower $(p<0.05)$ in the isolates of groups $\mathrm{B} 1$ and $\mathrm{E}$, whereas the isolates of groups B2 and C harbored the virulence determinants in adhesins, iron acquisition, protectins, and toxins categories significantly more frequently $(p<0.05)$. Moreover, isolates of group F carried VGs in the iron acquisition and protectins categories more frequently, but due to the small number of isolates, the differences were not statistically significant. Among the E. coli from sows, the isolates of group A harbored the VGs in adhesins, iron acquisition, and protectins categories significantly less frequently $(p<0.05)$. Two genes from the adhesins and iron acquisition categories occurred significantly more frequently $(p<0.05)$ in the isolates of group B1. Only one gene from the iron acquisition category was significantly associated $(p<0.05)$ with phylogroup B2. 
Table 2. Distribution of VGs in extended phylogenetic structure. The frequency of virulence genes among a particular E. coli phylogroup was compared to its prevalence in a group consisting of the isolates of all the other phylogenetic groups using the appropriate test for proportions.

\begin{tabular}{|c|c|c|c|c|c|c|c|c|c|c|c|c|c|c|c|c|}
\hline \multirow{3}{*}{ VG } & \multicolumn{16}{|c|}{ Number (\%) of E. coli Isolates with VGs within Phylogenetic Groups } \\
\hline & \multicolumn{8}{|c|}{ Piglets } & \multicolumn{8}{|c|}{ Sows } \\
\hline & $\begin{array}{c}A \\
n=24\end{array}$ & $\begin{array}{c}\text { B1 } \\
n=53\end{array}$ & $\begin{array}{c}\text { B2 } \\
n=5\end{array}$ & $\begin{array}{c}C \\
n=6\end{array}$ & $\begin{array}{c}D \\
n=3\end{array}$ & $\begin{array}{c}E \\
n=12\end{array}$ & $\begin{array}{c}F \\
n=3\end{array}$ & $\begin{array}{c}\text { NT } \\
n=4\end{array}$ & $\begin{array}{c}A \\
n=79\end{array}$ & $\begin{array}{c}\text { B1 } \\
\mathrm{n}=38\end{array}$ & $\begin{array}{c}\text { B2 } \\
n=4\end{array}$ & $\begin{array}{c}D \\
n=8\end{array}$ & $\begin{array}{c}E \\
n=3\end{array}$ & $\begin{array}{c}F \\
n=20\end{array}$ & $\begin{array}{c}\text { Clade I } \\
\mathrm{n}=4\end{array}$ & $\begin{array}{c}\text { NT } \\
n=8\end{array}$ \\
\hline \multicolumn{17}{|l|}{ Adhesins } \\
\hline fimH & $\begin{array}{c}23 \\
(95.8)\end{array}$ & $\begin{array}{c}51 \\
(96.2)\end{array}$ & $5(100)$ & $6(100)$ & $3(100)$ & $\begin{array}{c}12 \\
(100)\end{array}$ & $3(100)$ & $4(100)$ & $\begin{array}{c}77 \\
(97.5)\end{array}$ & $\begin{array}{c}38 \\
(100)\end{array}$ & $2(50.0)$ & $5(62.5)$ & $3(100)$ & $5(25.0)$ & $4(100)$ & $8(100)$ \\
\hline papA & 0 & $9(17.0)$ & $4(80.0)$ & 0 & 0 & 0 & 0 & 0 & 0 & $4(10.5)$ & $1(25.0)$ & $1(12.5)$ & 0 & $2(10.0)$ & 0 & 0 \\
\hline sfaS & $1(4.2)$ & 0 & $1(20.0)$ & 0 & 0 & 0 & 0 & 0 & 0 & 0 & 0 & 0 & 0 & 0 & 0 & 0 \\
\hline \multicolumn{17}{|c|}{ Iron acquisition } \\
\hline fyuA & $9(37.5)$ & $8(15.1)$ & $5(100)$ & $6(100)$ & 0 & 0 & $1(33.3)$ & 0 & $\begin{array}{c}11 \\
(13.9) \\
\end{array}$ & $6(15.8)$ & $2(50.0)$ & 0 & $1(33.3)$ & 0 & 0 & $3(37.5)$ \\
\hline iutA & $\begin{array}{c}13 \\
(54.2) \\
\end{array}$ & $\begin{array}{c}23 \\
(43.4) \\
\end{array}$ & $5(100)$ & $6(100)$ & $2(66.7)$ & $4(33.3)$ & $3(100)$ & 0 & $8(10.1)$ & $9(23.7)$ & $4(100)$ & $2(25.0)$ & 0 & $7(35.0)$ & 0 & $3(37.5)$ \\
\hline iroN & $9(37.5)$ & $\begin{array}{c}18 \\
(34.0)\end{array}$ & $5(100)$ & $6(100)$ & $1(33.3)$ & 0 & $3(100)$ & $1(25.0)$ & $7(8.9)$ & $\begin{array}{c}13 \\
(34.2)\end{array}$ & $1(25.0)$ & 0 & 0 & $5(25.0)$ & 0 & $3(37.5)$ \\
\hline ireA & $3(12.5)$ & $2(3.8)$ & $1(20.0)$ & $1(16.7)$ & 0 & 0 & 0 & 0 & $2(2.5)$ & $1(2.6)$ & 0 & 0 & 0 & 1 & 0 & $1(12.5)$ \\
\hline \multicolumn{17}{|l|}{ Protectins } \\
\hline kpsMTII & $2(8.3)$ & $1(1.9)$ & $4(80.0)$ & 0 & $1(33.3)$ & $1(8.3)$ & $2(66.7)$ & $1(25.0)$ & $2(2.5)$ & $3(7.9)$ & 0 & $1(12.5)$ & 0 & $1(5.0)$ & 0 & $3(37.5)$ \\
\hline kpsMTIII & 0 & $1(1.9)$ & 0 & 0 & 0 & 0 & 0 & 0 & $2(2.5)$ & 0 & 0 & 0 & 0 & 0 & 0 & 0 \\
\hline ompT & $6(25.0)$ & $\begin{array}{c}14 \\
(26.4) \\
\end{array}$ & $5(100)$ & $6(100)$ & $2(66.7)$ & 0 & $3(100)$ & 0 & $7(8.9)$ & $\begin{array}{c}11 \\
(28.9)\end{array}$ & 0 & 0 & 0 & $7(35.0)$ & 0 & $3(37.5)$ \\
\hline $\operatorname{traT}$ & $\begin{array}{c}19 \\
(79.2)\end{array}$ & $\begin{array}{c}49 \\
(92.5)\end{array}$ & $5(100)$ & $5(83.3)$ & $2(66.7)$ & $9(75.0)$ & $3(100)$ & $2(50.0)$ & $\begin{array}{c}36 \\
(45.6)\end{array}$ & $\begin{array}{c}25 \\
(65.8)\end{array}$ & $2(50.0)$ & $5(62.5)$ & $2(66.7)$ & $\begin{array}{c}13 \\
(65.0)\end{array}$ & $1(25.0)$ & $6(75.0)$ \\
\hline iss & $6(25.0)$ & $\begin{array}{c}14 \\
(26.4)\end{array}$ & $5(100)$ & $6(100)$ & $1(33.3)$ & 0 & $3(100)$ & 0 & $7(8.9)$ & $9(23.7)$ & 0 & 0 & 0 & $6(30.0)$ & 0 & $3(37.5)$ \\
\hline \multicolumn{17}{|l|}{ Toxins } \\
\hline cnf1 & 0 & $1(1.9)$ & $3(60.0)$ & $1(16.7)$ & 0 & 0 & 0 & 0 & 0 & 0 & 0 & 0 & 0 & 0 & 0 & 0 \\
\hline hlyA & 0 & $1(1.9)$ & $1(20.0)$ & 0 & 0 & 0 & 0 & 0 & 0 & 0 & 0 & 0 & 0 & 0 & 0 & 0 \\
\hline \multicolumn{17}{|c|}{ Biofilm formation } \\
\hline agn43 & $\begin{array}{c}20 \\
(83.3)\end{array}$ & $\begin{array}{c}19 \\
(35.8)\end{array}$ & $4(80.0)$ & $5(83.3)$ & $2(66.7)$ & $5(41.7)$ & $2(66.7)$ & $2(50.0)$ & $\begin{array}{c}41 \\
(51.9)\end{array}$ & $\begin{array}{c}19 \\
(50.0)\end{array}$ & $3(75.0)$ & $3(37.5)$ & $2(66.7)$ & $\begin{array}{c}10 \\
(50.0)\end{array}$ & $2(50.0)$ & $7(87.5)$ \\
\hline
\end{tabular}

The values significantly higher than among the other groups are indicated in yellow. The values significantly lower than among the other groups are indicated in blue. 


\subsection{Association between VGs}

The statistical analysis of the association between the VGs of the E. coli isolates is shown in Figure 2. Similar associations occurred in both groups of isolates from piglets (Figure 2, the part above the diagonal) and from sows (Figure 2, the part under the diagonal). Very strong associations were found between the genes omp $T$ and iss, with association coefficients of 0.96 and 0.87 in the isolates from piglets and sows, respectively. Strong associations were observed between the genes iroN and ompT, with the coefficients of 0.51 and 0.59 for E. coli from piglets and sows, respectively. The genes iroN and iss were also positively associated, with the coefficients of 0.48 and 0.54 among the E. coli from piglets and sows, respectively. Moderate associations were identified between the genes iut $A$ and iroN, with the association coefficients of 0.32 and 0.47 , and also between $i u t A$ and iss with coefficients of 0.31 and 0.35 for the isolates from piglets and sows, respectively. Additionally, in the group of isolates from piglets, moderate associations were found between the gene fyuA and the genes iroN, ompT and iss, with coefficients of $0.33,0.35$, and 0.37 , respectively. Among E. coli from sows, a moderate association between the genes iut $A$ and ompT with a coefficient of 0.39 was observed. Weak associations, with coefficients $\leq 0.3$, occurred between the remaining VGs in both groups of isolates from piglets and sows. Generally, significant associations were observed between the genes within the iron acquisition and protectins categories or between these two categories.

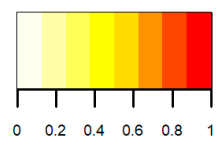

Goodman and Kruskal's tau coefficient

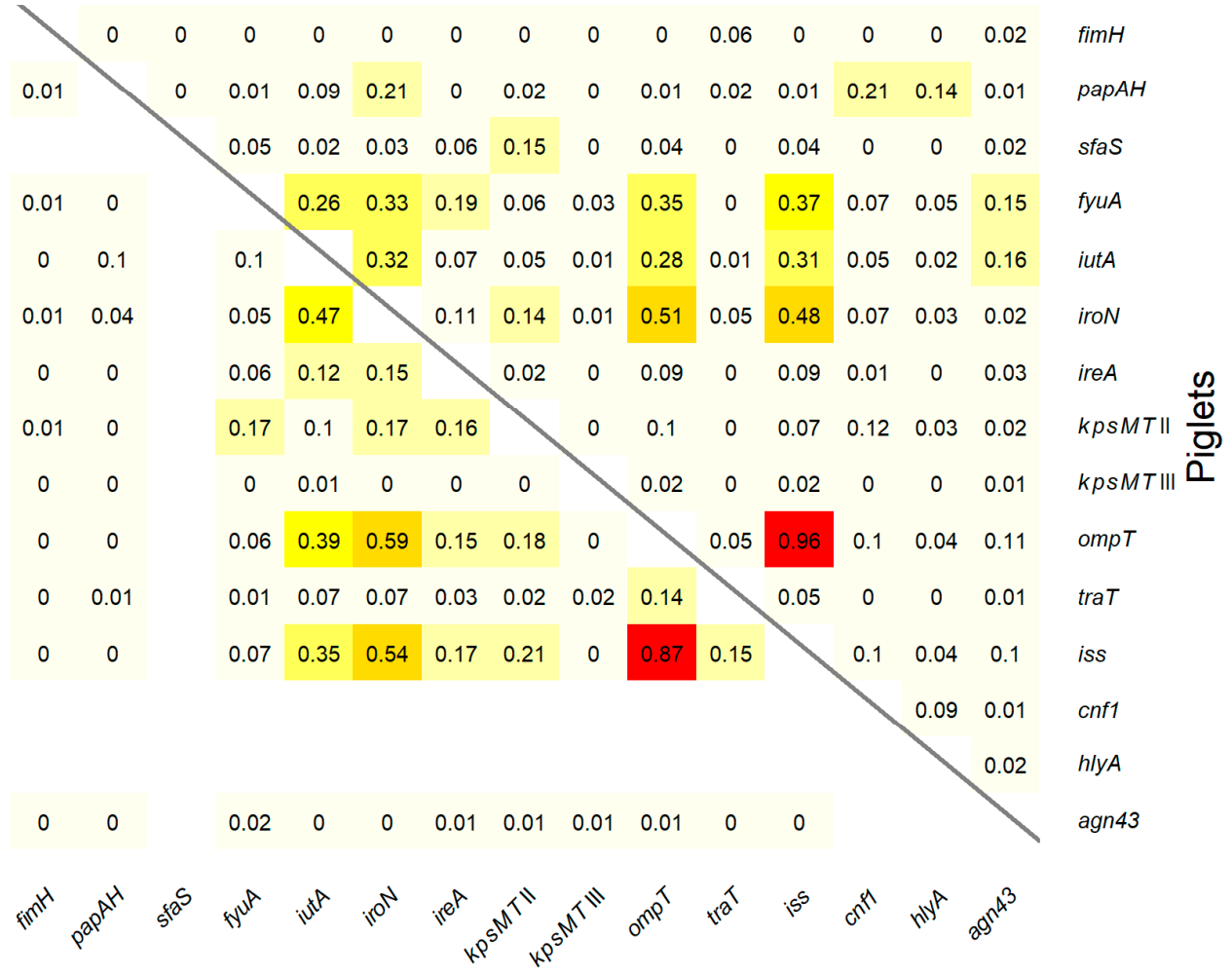

\section{Sows}

Figure 2. Statistical association between VGs of the E. coli isolates derived from piglets (the part above the diagonal) and sows (the part under the diagonal). No values were introduced in the case of undetected genes. 


\subsection{Genotypic Analysis of Fimbrial Operons for Type 1 and P Fimbriae}

The genes fim $H$ and papAH are considered to be genetic markers for type 1 and $\mathrm{P}$ fimbriae, respectively. The further analysis of this study encompassed the detection of the other crucial genes of type 1 and $\mathrm{P}$ fimbriae operons among the isolates positive for the fim $\mathrm{H}$ and $p a p A H$ genes, respectively. The complete set of six tested genes of the type 1 fimbrial operon occurred significantly more frequently in the isolates from piglets (55.1\%), as compared to sows (33.1\%), $p<0.0001$. Altogether, 13 various gene combinations of this operon were detected, 6 and 12 among the isolates from piglets and sows, respectively. The combination without one gene $(\operatorname{fim} A)$ was the most frequent in both groups of isolates, but significantly prevailed in E. coli from sows (54.9\%), as compared to piglets $(40.2 \%), p=0.0148$. The other gene combinations without two, three, four, and five genes within the type 1 fimbrial operon occurred less frequently (Figure 3A). Regarding the P fimbrial operon, the complete set of four tested genes was present in all E. coli positive for the papAH gene derived from piglets, but were not detected in any of the isolates from sows, $p<0.0001$. The PapG gene encodes the adhesin at the tip of the $P$ fimbriae and may be represented by one of three alleles: papGI, papGII, or papGIII. This gene occurred only among E. coli from piglets, where the allele pap GIII was identified most often (84.6\%). The other two alleles, papGI and papGII, were detected less frequently (7.7\% for both). Among the isolates from sows, two P fimbrial operon gene combinations were found, without one (papG) or two (papEF and papG) tested genes (Figure 3B).
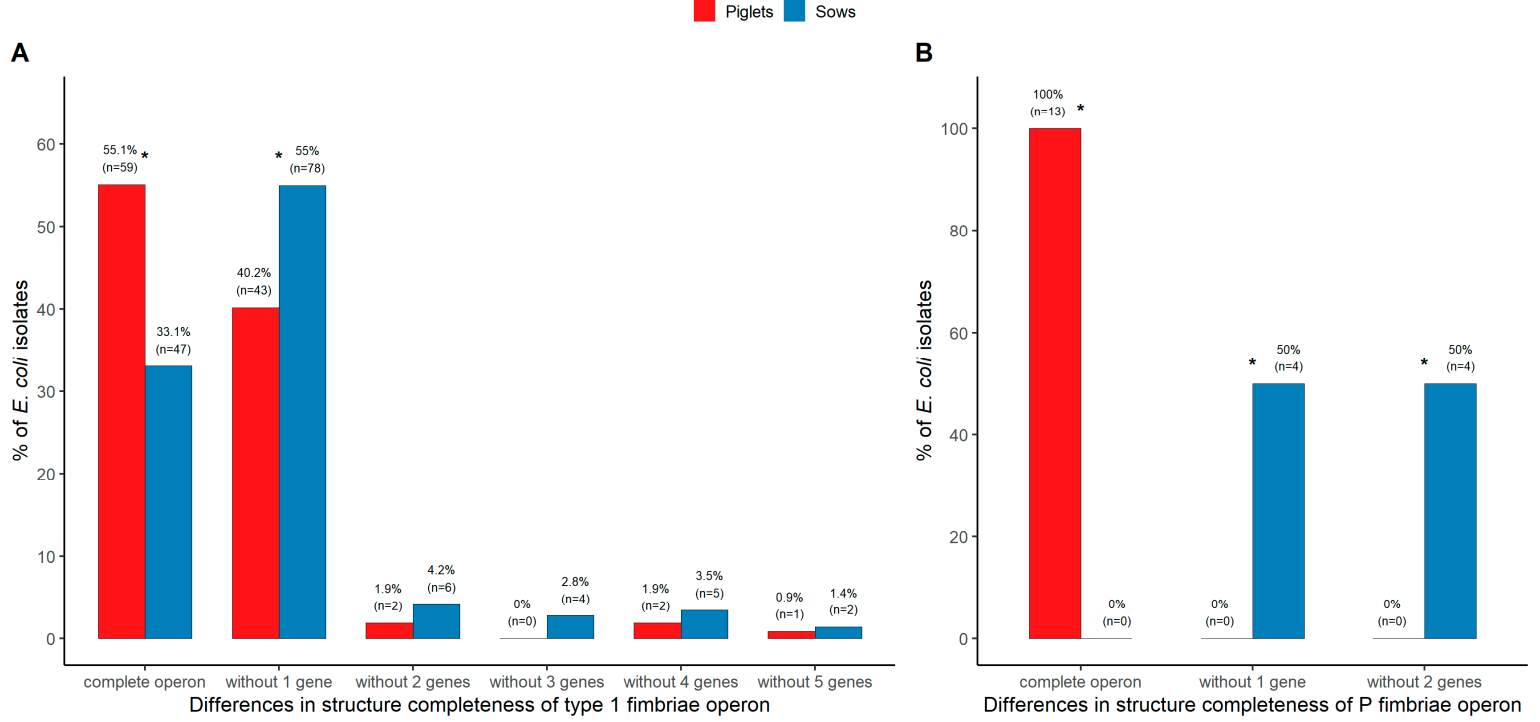

Figure 3. Frequency of the gene combinations within the structure of (A) type 1 and (B) $\mathrm{P}$ fimbriae operons among the E. coli isolates from piglets and sows. Note: The gene combinations within the structure of type 1 fimbriae operon: Complete operon: fimB-fimE-fimA-fimI-fimC-fimH; Without 1 gene: fimB-fimE-fimI-fimC-fim H; Without 2 genes: fimB-fimI-fimC-fimH, fimB-fimE-fimC-fimH, fimE-fimI-fimC-fimH; Without 3 genes: fimB-fimC-fimH, fimB-fimA-fimH, fimI-fimC-fimH, fimB-fimE-fimH; Without 4 genes: fimB-fimH, fim C-fimH, fimI-fimH; Without 5 genes: fim $H$. The gene combinations within the structure of $\mathrm{P}$ fimbriae operon: Complete operon: papAH-papC-papEF-papG; Without 1 gene: papAH-papC-papEF; Without 2 genes: papAH-papC. * Statistically significant.

\section{Discussion}

The present study examined for the first time, to our knowledge, the extended phylogenetic structure of commensal E. coli derived from two age groups of pigs (weaned piglets and sows) using the revised Clermont phylogenetic typing method [15]. Moreover, our study focused on the analysis of the extraintestinal virulence potential of these isolates. The results allowed us to gain a better understanding of the genetics of this population and the association between virulence gene carriage and phylogenetic type. 
Our previous study on the same set of E. coli isolates used the old Clermont typing scheme and showed the opposite distribution of phylogroups A and B1 among E. coli from piglets and sows. Phylogroup A dominated in isolates from sows, followed by B1 and D, while among E. coli from piglets, phylogroup B1 was the most frequent, followed by A and D. The least frequent in isolates from piglets and sows was phylogroup B2 [21]. The current study reclassified the basic phylogenetic structure using the revised Clermont protocol. The analysis revealed more complex phylogeny in both groups of isolates from piglets and sows. The main phylogenetic pattern of the new classification remains in agreement with the old one, with significant differences in distribution of phylogroups A and B1, where B1 group dominated among E. coli from piglets and A in isolates from sows. Moreover, phylogenetic groups $\mathrm{C}$ and $\mathrm{E}$ were significantly more frequent in the isolates from piglets. Conversely, phylogroup F significantly prevailed among the isolates from sows. One of the most important factors influencing the differences in phylogenetic structure may be the maturation of the digestive tract during growth of piglets and the replacement of milk with solid food in the diet [16,50]. Most changes were observed for conversion from $\mathrm{A}$ to $\mathrm{C}, \mathrm{D}$ to $\mathrm{E}$, and $\mathrm{D}$ to $\mathrm{F}$ in isolates from piglets. Among E. coli from sows, there also appeared new phylogroups, the most frequent changes occurred from $\mathrm{D}$ to $\mathrm{F}$, while a few isolates were reclassified into phylogroup E and clade I. There were a small number of isolates from piglets and sows, which according to the new classification, did not belong to any known phylogroup and therefore were assigned as NT. Using the new phylogenetic analysis approach, this study changed the designations of $27.2 \%$ and $31 \%$ of isolates from piglets and sows respectively, and retained about $70 \%$ of isolates in their original phylogenetic type. A significant reduction of phylogenetic group D in E. coli from piglets and sows can be considered the most striking reclassification result. It has been reported that the rate of reclassification is closely correlated with the species of the host and pathogenicity status of $E$. coli isolates. Among the human isolates, the changes ranged from $8.6 \%$ to $13 \%$ human fecal E. coli (HFEC) to $14 \%$ to $15 \%$ for neonatal meningitis E. coli (NMEC) and uropathogenic E. coli (UPEC) compared to the animal sources, where reclassification rates ranged from $21.6 \%$ for avian fecal E. coli (AFEC) to $53.8 \%$, with the greatest rate of reclassification observed for avian pathogenic E. coli (APEC) $[15,23]$.

Overall, the main pattern of phylogenetic designation of commensal E. coli from pigs in our earlier [21] and present studies is consistent with the other reports [12,18-20,51], namely the phylogroups $\mathrm{A}$ and B1 are more frequent than D and B2. There may occur a shift between the frequency of phylogroups A and B1, but these two groups together represent $70 \%$ or more of all E. coli isolates. The least frequent is phylogroup B2. Interestingly, the phylogenetic structure of porcine ExPEC is similar to the phylogeny of the commensal isolates. ExPEC from diseased pigs mostly belonged to phylogroups A and B1, while phylogroup B2 is usually the least numerous $[6,26,52,53]$. It has been reported that ExPEC isolated from piglets with septicemia, often pathogenic in experimental infections, fall into groups A and B1 [54]. These data are an obvious contrast with the fact that most ExPECs isolated from humans or companion animals belong to groups B2 and D [55].

Our study indicated that commensal E. coli from pigs carried the broad range of VGs typical for ExPEC, representing five functional categories: adhesins, iron acquisitions, protectins, toxin, and biofilm formation. According to the definition (Johnson et al. [10]) 17.3\% of E. coli isolates from piglets and $7.9 \%$ from sows were classified as ExPEC, despite the fact that they were derived from healthy animals. The other isolates in our collection also harbored VGs associated with the ability to cause extraintestinal disease, not only in swine but also in humans $[4,26]$. The results showed significant differences between isolates from piglets and sows. The majority of VGs were identified more frequently in isolates from piglets than from sows-seven of them: fimH, papAH, iutA, iroN, ompT, traT, and iss-with statistically significant differences. Such results indicated the greater proportion of potential ExPEC among commensal E. coli from weaned piglets than from sows, which is consistent with earlier studies $[21,56,57]$. Weaning is the crucial moment in the piglet's life. It is connected with stress during separation from the dam and with the changes in the diet, which causes environmental instability [50]. In consequence, a higher number of commensal E. coli acquired with the feed can settle 
themselves in the intestine. When the microbiota is stabilized, in older pigs, only the best adapted E. coli remains in the intestine [57].

The other aspect of possessing VGs is associated with gut colonization. Some specific combinations of genes could promote adaptations to a given environment. Extraintestinal VGs encoding adhesins, iron capture systems, toxins, and protectins have been correlated with successful gut colonization in humans, dogs, and piglets [1,58-60]. A study concerning colonization of E. coli in a sow's and her piglets' intestines showed that clones which were dominant at least once throughout the sampling period tended to have more VGs. E. coli bacteria with higher numbers of VGs, particularly of iron acquisition genes, were detected in more piglets and more often in the piglets, even after weaning. VGs typical for ExPEC promote successful colonization of the intestine in pigs [60].

Many studies have indicated that the most highly virulent human ExPEC strains, which cause urinary tract infection, neonatal septicemia, or meningitis, belong to group B2 or D and that the strains of these phylogroups harbor more virulence factors than the strains of the A and B1 groups $[7,13]$. Moreover, it has been reported that porcine ExPEC B2 isolates contained more virulence-associated genes than non-B2 isolates and these isolates had the strongest pathogenicity in a mouse infection model [26]. Another study found no significant differences in means (ranges) of VGs across different phylogenetic groups among ExPEC from pigs [6]. An earlier study also revealed that some strains of phylogenetic groups A, B1, and D were able to kill the mice and possessed virulence determinants [54]. Our results showed that isolates of phylogroups B2, C, and to a lesser extent F, (statistically not significant for F) from piglets carried VGs significantly more often, whereas isolates in phylogroups A and $\mathrm{B} 1$ did so less frequently. The analysis of the distribution of VGs within phylogenetic groups among E. coli from sows revealed no significant differences, the one exception being isolates of phylogroup A, which carried VGs significantly less frequently. Our results demonstrating the virulence potential of group B2 in isolates from piglets are consistent with those presented in the first, above-mentioned report concerning ExPEC [26]. On the other hand, it was also reported that VGs were distributed among four main phylogroups without significant differences in commensal porcine isolates [12], which is consistent with our analysis concerning E. coli from sows. The advantage of our study is the analysis of extended phylogenetic structure, which allows for more accurate designation of isolates to phylotypes. The appearance of phylogroup $C$ in isolates from piglets was a consequence of redistribution of E. coli from group A, and, what is interesting, the group C isolates harbored VGs more frequently than the isolates in other groups. The redistribution of isolates from phylogroup $\mathrm{D}$ in piglets to group $\mathrm{F}$ also distinguished $E$. coli with higher virulence potential, whereas the isolates redistributed from group D to E carried VGs less frequently. Our results are partially consistent with the study concerning extended phylotyping of human and avian ExPEC and commensal E. coli [23]. The aforementioned study reported that redistribution of APEC isolates from A to $C$ is connected with distinction of isolates with the lower number (group A) and higher number (group C) of pathogenicity-, resistance-, replicon-, and pathogenicity island-associated genes. The isolates that became reclassified as F from their original D designation appeared to harbor higher levels of these genes and indicated that APEC designated as the F phylogenetic type are probably highly pathogenic.

Mobile genetic elements transmitted via horizontal gene transfer play an important role in the evolution of E. coli. Most ExPEC VGs are clustered together on mobile genetic elements, usually on pathogenicity islands (PAI) or virulence plasmids, in unique organization. The analysis of associations between VGs may indicate which genes tend to occur in the same genetic element. Our analysis revealed that in commensal $E$. coli from piglets and sows there occurred similar associations between VGs, which suggests that the same genetic elements are present in E. coli isolates from piglets and sows. The most significant associations were identified between the genes within iron acquisition and protectins categories or between these two categories. Particularly the genes ompT and iss, iroN and $\operatorname{ompT}$, and also iroN and iss, are strongly associated. These genes usually occur together in the conserved virulence plasmidic (CVP) region, typical for the ExPEC virulence-associated plasmids [61]. 
Type 1 and P fimbriae are the major virulence factors of the UPEC strains. Type 1 fimbriae mediate adhesion, invasion, and intracellular formation of biofilm-like structures and are responsible primarily for bladder infection. P fimbriae are mainly related to pyelonephritis [62]. The fim $H$ gene is the most widespread virulence gene among the E. coli from piglets and sows, but our analysis of six genes forming the fimbrial operon demonstrated that among isolates positive for the gene fim $\mathrm{H}$, there occurred a large variety of incomplete combinations of these genes. The complete set of six tested genes of the type 1 fimbrial operon occurred significantly more frequently in the isolates from piglets than from sows. The combination without one gene (fimA) was the most frequent in both groups of isolates, but significantly prevailed in E. coli from sows. Incompleteness of this operon is rather common in commensal E. coli from pigs, reaching $44.9 \%$ and $66.9 \%$ among isolates from piglets and sows, respectively. The previous studies indicated that many human commensal isolates positive for the fim $H$ gene showed a lack of type 1 fimbriae due to the deletion or lack of the expression of one or more of the type 1 fimbriae operon genes [63]. Such results suggest that the fimH gene is not a good marker of type 1 fimbriae, much better would be the fim $A$ gene. The analysis of the completeness of the $P$ fimbrial operon revealed that all E. coli positive for the papAH gene were derived from piglets that possessed the complete set of four tested genes. The $p a p G$ gene was represented the most often by the allele papGIII mainly associated with lower urinary tract infections (cystitis) [64]. The complete P fimbrial operon was not detected in any of the isolates from sows, indicating that these E. coli cannot express $P$ fimbriae.

It has been reported that porcine commensal E. coli isolates carried large numbers of virulence-associated genes. Some of these isolates belong to ST131 and ST117, representative of pandemic ExPEC clones that cause hospital- and community-acquired infections in humans worldwide [12]. Moreover, the clonal complex 10 (CC10) was identified as the predominant clonal group within the collection of porcine commensal E. coli from healthy Australian food-production pigs. CC10 is a resident of the intestinal tract of humans, food-production animals, companion animals, and wild animals. E. coli CC10 members frequently carried VGs and they are increasingly reported as human and animal extraintestinal pathogens $[6,12,33,34]$. Our results and above-mentioned reports [12,34] suggest that commensal E. coli from pigs may have zoonotic potential associated with a specific clonal lineage within phylogenetic groups.

\section{Conclusions}

This study analyzed the extended phylogenetic structure and extraintestinal potential of commensal E. coli isolates from post-weaning piglets and sows. Application of the revised Clermont phylogenetic typing method revealed more complex phylogeny and significant differences in the proportion of phylogroups in both pools of isolates from piglets and sows. Particularly the revised phylogenetic assignment of $\mathrm{A}$ and $\mathrm{D}$ phylogroup isolates allowed us to distinguish $E$. coli with significantly higher (transition from $\mathrm{A}$ to $\mathrm{C}$ and from $\mathrm{D}$ to $\mathrm{F}$ ) or lower (transition from $\mathrm{D}$ to $\mathrm{E}$ ) virulence potential in isolates from piglets. The analysis of the VG frequencies showed that commensal E. coli from pigs, particularly from post-weaning piglets, constitute a substantial reservoir of VGs typical for ExPEC. The VGs preferentially accumulated in the isolates of phylogroups B2, C, and to a lesser extent F, from piglets, while in isolates from sows, VGs were distributed more evenly. On the other hand, generally in the phylogenetic structure of commensal $E$. coli from pigs, group B1 prevailed in piglets and group $\mathrm{A}$ in sows. Knowing that ExPEC from diseased pigs mostly belong to phylogroups $\mathrm{A}$ and B1, we cannot exclude that commensal strains of groups A and B1 may also pose a potential threat of extraintestinal infection. The probability of expression of type 1 and $P$ fimbriae resulting from the presence of the complete operons was significantly higher in isolates from piglets. Recently, ExPEC infections have become more common in the pig industry [25-27], so it is important to understand the population structure of porcine commensal E. coli. We should also be aware of the reservoir of VGs carried by commensal E. coli from pigs in terms of the public health threat. This study provides a good starting point for further, more detailed genomic investigation. 
Supplementary Materials: The following are available online at http://www.mdpi.com/1660-4601/17/1/366/s1. Table S1: Comparison of phylogenetic structure of E. coli isolates from piglets and sows using previous and revised Clermont phylogenetic typing method.

Author Contributions: E.B. and K.B.-C. conceived and designed the experiments. E.B., A.K. and J.M.-P. performed the experiments. E.B., A.K., J.M.-P. and K.B.-C. analyzed the data. M.W. performed all statistical analysis. E.B. wrote the paper. All authors have read and agreed to the published version of the manuscript.

Funding: This research was partially funded by the Polish Ministry of Science and Higher Education grant N304 412538.

Acknowledgments: We would like to thank Wanda Tomala, for skillful technical assistance in our work.

Conflicts of Interest: The authors declare no conflict of interest.

\section{References}

1. Tenaillon, O.; Skurnik, D.; Picard, B.; Denamur, E. The population genetics of commensal Escherichia coli. Nat. Rev. Microbiol. 2010, 8, 207-217. [CrossRef] [PubMed]

2. Köhler, C.D.; Dobrindt, U. What defines extraintestinal pathogenic Escherichia coli? Int. J. Med. Microbiol. 2011, 301, 642-647. [CrossRef] [PubMed]

3. Starčič, E.M.; Žgur-Bertok, D. Virulence potential for extraintestinal infections among commensal Escherichia coli isolated from healthy humans-The Trojan horse within our gut. FEMS Microbiol. Lett. 2015, 362, fnu061.

4. Johnson, J.R.; Russo, T.A. Molecular epidemiology of extraintestinal pathogenic (uropathogenic) Escherichia coli. Int. J. Med. Microbiol. 2005, 295, 383-404. [CrossRef]

5. Bélanger, L.; Garenaux, A.; Harel, J.; Boulianne, M.; Nadeau, E.; Dozois, C.M. Escherichia coli from animal reservoirs as a potential source of human extraintestinal pathogenic E. coli. FEMS Immunol. Med. Microbiol. 2011, 62, 1-10. [CrossRef]

6. Tan, C.; Tang, X.; Zhang, X.; Ding, Y.; Zhao, Z.; Wu, B.; Cai, X.; Liu, Z.; He, Q.; Chen, H. Serotypes and virulence genes of extraintestinal pathogenic Escherichia coli isolates from diseased pigs in China. Vet. J. 2012, 192, 483-488. [CrossRef]

7. Picard, B.; Garcia, J.S.; Gouriou, S.; Duriez, P.; Brahimi, N.; Bingen, E.; Elion, J.; Denamur, E. The link between phylogeny and virulence in Escherichia coli extraintestinal infection. Infect. Immun. 1999, 67, 546-553. [CrossRef]

8. Sarowska, J.; Futoma-Koloch, B.; Jama-Kmiecik, A.; Frej-Madrzak, M.; Ksiazczyk, M.; Bugla-Ploskonska, G.; Choroszy-Krol, I. Virulence factors, prevalence and potential transmission of extraintestinal pathogenic Escherichia coli isolated from different sources: Recent reports. Gut Pathog. 2019, 11, 10. [CrossRef]

9. Wasiński, B. Extra-intestinal pathogenic Escherichia coli-threat connected with food-borne infections. Ann. Agric. Environ. Med. 2019. [CrossRef]

10. Johnson, J.R.; Murray, A.C.; Gajewski, A.; Sullivan, M.; Snippes, P.; Kuskowski, M.A.; Smith, K.E. Isolation and molecular characterization of nalidixic acid-resistant extraintestinal pathogenic Escherichia coli from retail chicken products. Antimicrob. Agents Chemother. 2003, 47, 2161-2168. [CrossRef]

11. Venturini, C.; Hassan, K.A.; Chowdhury, P.R.; Paulsen, I.T.; Walker, M.J.; Djordjevic, S.P. Sequences of two related multiple antibiotic resistance virulence plasmids sharing a unique IS26-related molecular signature isolated from different Escherichia coli pathotypes from different hosts. PLoS ONE 2013, 8, e78862. [CrossRef] [PubMed]

12. Reid, C.J.; Wyrsch, E.R.; Chowdhury, P.R.; Zingali, T.; Liu, M.; Darling, A.E.; Chapman, T.A.; Djordjevic, S.P. Porcine commensal Escherichia coli: A reservoir for class 1 integrons associated with IS26. Microb. Genom. 2017, 3, 12. [CrossRef] [PubMed]

13. Johnson, J.R.; Oswald, E.; O’Bryan, T.T.; Kuskowski, M.A.; Spanjaard, L. Phylogenetic distribution of virulence-associated genes among Escherichia coli isolates associated with neonatal bacterial meningitis in the Netherlands. J. Infect. Dis. 2002, 185, 774-784. [CrossRef] [PubMed]

14. Nowrouzian, F.L.; Wold, A.E.; Adlerberth, I. Escherichia coli strains belonging to phylogenetic group B2 have superior capacity to persist in the intestinal microflora of infants. J. Infect. Dis. 2005, 191, 1078-1083. [CrossRef] [PubMed] 
15. Clermont, O.; Christenson, J.K.; Denamur, E.; Gordon, D.M. The Clermont Escherichia coli phylo-typing method revisited: Improvement of specificity and detection of new phylo-groups. Environ. Microbiol. Rep. 2013, 5, 58-65. [CrossRef] [PubMed]

16. Escobar-Páramo, P.; Le Menac'h, A.; Le Gall, T.; Amorin, C.; Gouriou, S.; Picard, B.; Skurnik, D.; Denamur, E. Identification of forces shaping the commensal Escherichia coli genetic structure by comparing animal and human isolates. Environ Microbiol. 2006, 8, 1975-1984. [CrossRef]

17. Gordon, D.M.; Cowling, A. The distribution and genetic structure of Escherichia coli in Australian vertebrates: Host and geographic effects. Microbiology 2003, 149, 3575-3586. [CrossRef]

18. Carlos, C.; Pires, M.M.; Stoppe, N.C.; Hachich, E.M.; Sato, M.I.; Gomes, T.A.; Amaral, L.A.; Ottoboni, L.M. Escherichia coli phylogenetic group determination and its application in the identification of the major animal source of fecal contamination. BMC Microbiol. 2010, 10, 161. [CrossRef]

19. Cortés, P.; Blanc, V.; Mora, A.; Dahbi, G.; Blanco, J.E.; Blanco, M.; López, C.; Andreu, A.; Navarro, F.; Alonso, M.P.; et al. Isolation and characterization of potentially pathogenic antimicrobial-resistant Escherichia coli strains from chicken and pig farms in Spain. Appl. Environ. Microbiol. 2010, 76, 2799-2805. [CrossRef]

20. Dixit, S.M.; Gordon, D.M.; Wu, X.Y.; Chapman, T.; Kailasapathy, K.; Chin, J.J. Diversity analysis of commensal porcine Escherichia coli-associations between genotypes and habitat in the porcine gastrointestinal tract. Microbiology 2004, 150, 1735-1740. [CrossRef]

21. Bok, E.; Mazurek, J.; Pusz, P.; Stosik, M.; Baldy-Chudzik, K. Age as a factor influencing diversity of commensal E. coli microflora in pigs. Pol. J. Microbiol. 2013, 62, 165-171. [CrossRef] [PubMed]

22. Clermont, O.; Bonacorsi, S.; Bingen, E. Rapid and simple determination of the Escherichia coli phylogenetic group. Appl. Environ. Microbiol. 2000, 66, 4555-4558. [CrossRef] [PubMed]

23. Logue, C.M.; Wannemuehler, Y.; Nicholson, B.A.; Doetkott, C.; Barbieri, N.L.; Nolan, L.K. Comparative analysis of phylogenetic assignment of human and avian ExPEC and fecal commensal Escherichia coli using the (previous and revised) Clermont phylogenetic typing methods and its impact on avian pathogenic Escherichia coli (APEC) classification. Front. Microbiol. 2017, 8, 283. [CrossRef] [PubMed]

24. Russo, T.A.; Johnson, J.R. Medical and economic impact of extraintestinal infections due to Escherichia coli: Focus on an increasingly important endemic problem. Microbes Infect. 2003, 5, 449-456. [CrossRef]

25. Fairbrother, J.M.; Gyles, C. Colibacillosis. In Diseases of Swine, 10th ed.; Zimmerman, J.J., Karriker, L.A., Ramirez, A., Schwartz, K.J., Stevenson, G.W., Eds.; John Wiley \& Sons: Hoboken, NJ, USA, 2012; pp. 723-749.

26. Zhu, Y.; Dong, W.; Ma, J.; Yuan, L.; Hejair, H.M.; Pan, Z.; Liu, G.; Yao, H. Characterization and virulence clustering analysis of extraintestinal pathogenic Escherichia coli isolated from swine in China. BMC Vet. Res. 2017, 13, 94. [CrossRef]

27. Spindola, M.G.; Cunha, M.P.V.; Moreno, L.Z.; Amigo, C.R.; Silva, A.P.S.; Parra, B.M.; Poor, A.P.; de Oliveira, C.H.; Perez, B.P.; Knöbl, T.; et al. Genetic diversity, virulence genotype and antimicrobial resistance of uropathogenic Escherichia coli (UPEC) isolated from sows. Vet. Q. 2018, 38, 79-87. [CrossRef]

28. Zong, B.; Zhang, Y.; Wang, X.; Liu, M.; Zhang, T.; Zhu, Y.; Zheng, Y.; Hu, L.; Li, P.; Chen, H.; et al. Characterization of multiple type-VI secretion system (T6SS) VgrG proteins in the pathogenicity and antibacterial activity of porcine extra-intestinal pathogenic Escherichia coli. Virulence 2019, 10, 118-132. [CrossRef]

29. Jakobsen, L.; Spangholm, D.J.; Pedersen, K.; Jensen, L.B.; Emborg, H.D.; Agersø, Y.; Aarestrup, F.M.; Hammerum, A.M.; Frimodt-Møller, N. Broiler chickens, broiler chicken meat, pigs and pork as sources of ExPEC related virulence genes and resistance in Escherichia coli isolates from community-dwelling humans and UTI patients. Int. J. Food Microbiol. 2010, 142, 264-272. [CrossRef]

30. Manges, A.R.; Johnson, J.R. Reservoirs of extraintestinal pathogenic Escherichia coli. Microbiol. Spectrum 2015, 3. [CrossRef]

31. Mellata, M. Human and avian extraintestinal pathogenic Escherichia coli: Infections, zoonotic risks, and antibiotic resistance trends. Foodborne Pathog. Dis. 2013, 10, 916-932. [CrossRef]

32. Tan, C.; Xu, Z.; Zheng, H.; Liu, W.; Tang, X.; Shou, J.; Wu, B.; Wang, S.; Zhao, G.P.; Chen, H. Genome sequence of a porcine extraintestinal pathogenic Escherichia coli strain. J. Bacteriol. 2011, 193, 5038. [CrossRef]

33. Manges, A.R.; Harel, J.; Masson, L.; Edens, T.J.; Portt, A.; Reid-Smith, R.J.; Zhanel, G.G.; Kropinski, A.M.; Boerlin, P. Multilocus sequence typing and virulence gene profiles associated with Escherichia coli from human and animal sources. Foodborne Pathog. Dis. 2015, 12, 302-310. [CrossRef] [PubMed] 
34. Reid, C.J.; DeMaere, M.Z.; Djordjevic, S.P. Australian porcine clonal complex 10 (CC10) Escherichia coli belong to multiple sublineages of a highly diverse global CC10 phylogeny. Microb. Genom. 2019, 5, e000225. [CrossRef] [PubMed]

35. Lescat, M.; Clermont, O.; Woerther, P.L.; Glodt, J.; Dion, S.; Skurnik, D.; Djossou, F.; Dupont, C.; Perroz, G.; Picard, B.; et al. Commensal Escherichia coli strains in Guiana reveal a high genetic diversity with host-dependant population structure. Environ. Microbiol. Rep. 2013, 5, 49-57. [CrossRef] [PubMed]

36. Clermont, O.; Lescat, M.; O’Brien, C.L.; Gordon, D.M.; Tenaillon, O.; Denamur, E. Evidence for a human-specific Escherichia coli clone. Environ. Microbiol. 2008, 10, 1000-1006.

37. Clermont, O.; Gordon, D.M.; Brisse, S.; Walk, S.T.; Denamur, E. Characterization of the cryptic Escherichia lineages: Rapid identification and prevalence. Environ. Microbiol. 2011, 13, 2468-2477. [CrossRef]

38. Johnson, J.R.; Stell, A.L. Extended virulence genotypes of Escherichia coli strains from patients with urosepsis in relation to phylogeny and host compromise. J. Infect. Dis. 2000, 181, 261-272. [CrossRef] [PubMed]

39. Johnson, J.R.; O'Bryan, T.T. Detection of the Escherichia coli group 2 polysaccharide capsule synthesis gene kpsM by a rapid and specific PCR-based assay. J. Clin. Microbiol. 2004, 42, 1773-1776. [CrossRef]

40. Mellata, M.; Ameiss, K.; Mo, H.; Curtiss, R. Characterization of the contribution to virulence of three large plasmids of avian pathogenic Escherichia coli chi7122 (O78:K80:H9). Infect. Immun. 2010, 78, 1528-1541. [CrossRef]

41. Yamamoto, S.; Terai, A.; Yuri, K.; Kurazono, H.; Takeda, Y.; Yoshida, O. Detection of urovirulence factors in Escherichia coli by multiplex polymerase chain reaction. FEMS Immunol. Med. Microbiol. 1995, 12, 85-90. [CrossRef]

42. Restieri, C.; Garriss, G.; Locas, M.C.; Dozois, C.M. Autotransporter-encoding sequences are phylogenetically distributed among Escherichia coli clinical isolates and reference strains. Appl. Environ. Microbiol. 2007, 73, 1553-1562. [CrossRef] [PubMed]

43. Blumer, C.; Kleefeld, A.; Lehnen, D.; Heintz, M.; Dobrindt, U.; Nagy, G.; Michaelis, K.; Emödy, L.; Polen, T.; Rachel, R.; et al. Regulation of type 1 fimbriae synthesis and biofilm formation by the transcriptional regulator LrhA of Escherichia coli. Microbiology 2005, 151, 3287-3298. [CrossRef] [PubMed]

44. Schwan, W.R.; Lee, J.L.; Lenard, F.A.; Matthews, B.T.; Beck, M.T. Osmolarity and pH growth conditions regulate fim gene transcription and type 1 pilus expression in uropathogenic Escherichia coli. Infect. Immun. 2002, 70, 1391-1402. [CrossRef] [PubMed]

45. Ewers, C.; Li, G.; Wilking, H.; Kiessling, S.; Alt, K.; Antáo, E.M.; Laturnus, C.; Diehl, I.; Glodde, S.; Homeier, T.; et al. Avian pathogenic, uropathogenic, and newborn meningitis-causing Escherichia coli: How closely related are they? Int. J. Med. Microbiol. 2007, 297, 163-176. [CrossRef] [PubMed]

46. Chapman, T.A.; Wu, X.Y.; Barchia, I.; Bettelheim, K.A.; Driesen, S.; Trott, D.; Wilson, M.; Chin, J.J. Comparison of virulence gene profiles of Escherichia coli strains isolated from healthy and diarrheic swine. Appl. Environ. Microbiol. 2006, 72, 4782-4795. [CrossRef]

47. Benjamini, Y.; Hochberg, Y. Controlling the false discovery rate: A practical and powerful approach to multiple testing. J. R. Statist. Soc. B 1995, 57, 289-300. [CrossRef]

48. Lindstrom, M.J.; Bates, D.M. Nonlinear mixed effects models for repeated measures data. Biometrics 1990, 46, 673-687. [CrossRef]

49. R Core Team. A Language and Environment for Statistical Computing. 2019. Available online: https: //repo.bppt.go.id/cran/web/packages/dplR/vignettes/intro-dplR.pdf (accessed on 31 October 2019).

50. Spencer, B.T.; Howell, P.G. Some husbandry factors influencing weaning stresses in piglets. J. S. Afr. Vet. Assoc. $1989,60,62-64$.

51. Bibbal, D.; Dupouy, V.; Prère, M.F.; Toutain, P.L.; Bousquet-Mélou, A. Relatedness of Escherichia coli strains with different susceptibility phenotypes isolated from swine feces during ampicillin treatment. Appl. Environ. Microbiol. 2009, 75, 2999-3006. [CrossRef]

52. Liu, C.; Zheng, H.; Yang, M.; Xu, Z.; Wang, X.; Wei, L.; Tang, B.; Liu, F.; Zhang, Y.; Ding, Y.; et al. Genome analysis and in vivo virulence of porcine extraintestinal pathogenic Escherichia coli strain PCN033. BMC Genom. 2016, 16, 717. [CrossRef]

53. Ding, Y.; Tang, X.; Lu, P.; Wu, B.; Xu, Z.; Liu, W.; Zhang, R.; Bei, W.; Chen, H.; Tan, C. Clonal analysis and virulent traits of pathogenic extraintestinal Escherichia coli isolates from swine in China. BMC Vet. Res. 2012, 8, 140. [CrossRef] [PubMed] 
54. Dezfulian, H.; Batisson, I.; Fairbrother, J.M.; Lau, P.C.; Nassar, A.; Szatmari, G.; Harel, J. Presence and characterization of extraintestinal pathogenic Escherichia coli virulence genes in F165-positive E. coli strains isolated from diseased calves and pigs. J. Clin. Microbiol. 2003, 41, 1375-1385. [CrossRef] [PubMed]

55. Maynard, C.; Bekal, S.; Sanschagrin, F.; Levesque, R.C.; Brousseau, R.; Masson, L.; Lariviere, S.; Harel, J. Heterogeneity among virulence and antimicrobial resistance gene profiles of extraintestinal Escherichia coli isolates of animal and human origin. J. Clin. Microbiol. 2004, 42, 5444-5452. [CrossRef]

56. Katouli, M.; Lund, A.; Wallgren, P.; Kuhn, I.; Soderlind, O.; Mollby, R. Phenotypic characterization of intestinal Escherichia coli of pigs during suckling, postweaning, and fattening periods. Appl. Environ. Microbiol. 1995, $61,778-783$.

57. Ahmed, S.; Olsen, J.E.; Herrero-Fresno, A. The genetic diversity of commensal Escherichia coli strains isolated from non-antimicrobial treated pigs varies according to age group. PLoS ONE 2017, 12, e0178623. [CrossRef] [PubMed]

58. Nowrouzian, F.L.; Adlerberth, I.; Wold, A.E. Enhanced persistence in the colonic microbiota of Escherichia coli strains belonging to phylogenetic group B2: Role of virulence factors and adherence to colonic cells. Microbes Infect. 2006, 8, 834-840. [CrossRef]

59. Johnson, J.R.; Clabots, C.; Kuskowski, M.A. Multiple-host sharing, long-term persistence, and virulence of Escherichia coli clones from human and animal household members. J. Clin. Microbiol. 2008, 46, 4078-4082. [CrossRef]

60. Schierack, P.; Walk, N.; Ewers, C.; Wilking, H.; Steinrück, H.; Filter, M.; Wieler, L.H. ExPEC-typical virulence-associated genes correlate with successful colonization by intestinal E. coli in a small piglet group. Environ. Microbiol. 2008, 10, 1742-1751. [CrossRef]

61. Lemaître, C.; Mahjoub-Messai, F.; Dupont, D.; Caro, V.; Diancourt, L.; Bingen, E.; Bidet, P.; Bonacorsi, S. A conserved virulence plasmidic region contributes to the virulence of the multiresistant Escherichia coli meningitis strain S286 belonging to phylogenetic group C. PLoS ONE 2013, 8, e74423. [CrossRef]

62. Lüthje, P.; Brauner, A. Virulence factors of uropathogenic E. coli and their interaction with the host. Adv. Microb. Physiol. 2014, 65, 337-372.

63. Pusz, P.; Bok, E.; Mazurek, J.; Stosik, M.; Baldy-Chudzik, K. Type 1 fimbriae in commensal Escherichia coli derived from healthy humans. Acta Biochim. Pol. 2014, 61, 389-392. [CrossRef] [PubMed]

64. Lane, M.C.; Mobley, H.L.T. Role of P-fimbrial-mediated adherence in pyelonephritis and persistence of uropathogenic Escherichia coli (UPEC) in the mammalian kidney. Kidney Int. 2007, 72, 19-25. [CrossRef] [PubMed]

(C) 2020 by the authors. Licensee MDPI, Basel, Switzerland. This article is an open access article distributed under the terms and conditions of the Creative Commons Attribution (CC BY) license (http://creativecommons.org/licenses/by/4.0/). 